\title{
Photoacclimation of Ulva rigida and $U$. rotundata (Chlorophyta) arranged in canopies
}

\author{
Juan J. Vergara*, Marta Sebastián**, J. Lucas Pérez-Lloréns, Ignacio Hernández \\ Departamento de Ecología, Facultad de Ciencias del Mar, Universidad de Cádiz, E-11510 Puerto Real, Cádiz, Spain
}

\begin{abstract}
Photosynthetic acclimation of Ulva rigida and U. rotundata arranged in canopies was assessed by combining laboratory and field experiments. Changes in the light field caused by the selfshading of Ulva thalli resulted in an instantaneous effect on the photosynthetic parameters. Photosynthetic efficiency decreased from the top of the canopy to the bottom as the photosynthetic active radiation/photosynthetic usable radiation ratio (PAR/PUR) increased. In contrast, the light compensation point showed an opposite pattern. Other photosynthetic parameters, light-saturated rate of photosynthesis and dark respiration, were unaffected. Both species acclimated to light gradients within the canopies, both in the laboratory and in the field, by changes in capacity of light capture and in photosynthetic performance: total chlorophyll concentration and absorptance decreased in the upper Ulva thalli, while the C:N ratio showed an opposite pattern. With regard to photosynthetic performance, area-normalized photosynthesis rate under saturating and subsaturating light increased towards the bottom of the canopies, while dark respiration was higher in the upper surface of the mats. The photoacclimation of canopies in which the thalli were randomly mixed 2 times per day showed a highly variable response: $U$. rigida thalli, submitted to similar mean irradiances and with comparable fluctuations in the light regime, showed high variability in chlorophyll content and growth rate, which, in turn, were not correlated. Canopies of $U$. rigida were also set up in the field. Total chlorophyll displayed a vertical profile similar to those obtained under laboratory conditions. Growth rate decreased exponentially through the canopy, but remained positive despite the low photon fluence rate reaching the bottom of the mat. Chlorophyll profiles in natural $U$. rotundata canopies suggested a structured arrangement of thalli in the field. Light attenuation through the Ulva canopies and photoacclimation due to this arrangement should be included in any model of primary production in these systems.
\end{abstract}

KEY WORDS: Canopy PAR/PUR ratio Photoacclimation Photosynthesis - Ulva rigida - Ulva rotundata

\section{INTRODUCTION}

Soft sediments and mudflats of shallow coastal zones undergoing eutrophication, such as some estuaries and bays, are often dominated by green algae of the order Ulvales, mainly Ulva and Enteromorpha (Schramm \& Nienhuis 1996, Valiela et al. 1997). Ulva thalli are frequently arranged in mats, canopy-like structures where a high thallus area index (TAI; a concept analogous to the leaf area index for vascular plant sporophytes) is observed in the field (Hernández et al. 1997). In these circumstances, the canopies undergo marked

\footnotetext{
•E-mail: juanjose.vergara@uca.es

- Present address: Departamento de Ecología, Facultad de Ciencias, Universidad de Málaga, E-29071 Málaga, Spain
}

changes in light climate caused by a self-shading effect (Vergara et al. 1997). The persistence of Ulva canopies can be controlled by tidal movements. In mudflats and flumes, the water motion and turbulence during ebb and flow may cause mixing of the layers within the canopy or even loss of the whole structure Conversely, in some areas the canopies may be stable keeping their structure during high tide, even as floating thick mats.

Light is also strongly attenuated over the canopy by the water column, especially at high tides. Recently, Vergara et al. (1997) showed that Ulva blades arranged in canopies are not optically neutral, since they preferentially absorb the blue and red regions of the light spectrum. Thus, the light spectrum becomes progressively more green-enriched as it passes through the 
mats. Consequently, the change in the spectral composition of the light reduces the photosynthetic active radiation/photosynthetic usable radiation ratio (PAR/PUR) (Morel et al. 1987) through the canopies.

In spite of numerous reports related to self-shading effects in phytoplankton (see Kirk 1994), and photoacclimation in vascular plant canopies (Terashima \& Hikosaka 1995), studies on photosynthetic metabolism within canopies in marine macroalgae are scarce. Measurement of light attenuation in Codium bursa, a balloon-like green alga, indicated that it absorbs most incident light (Geertz-Hansen et al. 1994). Microsensor studies for light and oxygen distribution were carried out by Lassen et al. (1994) in C. fragile, due to its siphonal and soft thallus. These authors reported steep light and oxygen gradients within a thallus on a scale of millimetres. Salles et al. (1996) showed changes in the spectral composition of light under canopies of intertidal macroalgae. In their study, Porphyra leucosticta growth rates were lowered by a canopy of 1 blade, despite the same light intensity, which is indicative of a lower PAR/PUR ratio under the canopy. Recently, Krause-Jensen et al. (1996) showed that productivity declined with depth in mats of Chaetomorpha linum, reflecting a pronounced self-shading within these mats.

Ulva species are ubiquitous on the sediments of the shallow coastal zones of southern Spain. Ecophysiological studies in different coastal zones of this region have focused on the photoacclimation of Ulva species under laboratory conditions (Pérez-Lloréns et al. 1996), the biomass, the dynamics of growth and net primary production of this species (Hernández et al. 1997) and the seasonal photosynthetic performance and light attenuation in Ulva canopies (Vergara et al. 1997). In these studies, a main conclusion was that light attenuation within Ulva canopies may be an important factor in the regulation of primary productivity, while photoacclimation of Ulva thalli to a canopy arrangement could enhance productivity compared to a hypothetical constant response within the mat.

The aim of this work was to assess the photoacclimation effect on photosynthetic performance, thallus elemental composition and growth within Ulva canopies. Canopies were maintained both under laboratory conditions and in the field. To simulate the possible mixing caused by tidal movements, the study was conducted in 2 ways: (1) by keeping a structured canopy during the whole period of study and (2) by randomly mixing the thalli within the mat twice a day. This work was performed in 2 Ulva species that bloom in shallow coastal zones of southern Spain: U. rigida and U. rotundata. The results obtained in this study indicate that the photoacclimation of Ulva arranged in canopies must be considered when planning a global model to estimate the primary productivity of these systems.

\section{MATERIAL AND METHODS}

Field sampling. Two UIva species that bloom on the soft sediments of the coastal zones of southern Spain were selected. U. rigida C. Agardh was collected from a. creek at Los Toruños, a salt marsh belonging to the Cádiz Bay Natural Park, in the vicinity of the Faculty of Marine Sciences (Puerto Real, Cádiz). U. rotundata Bliding was collected from the Palmones river estuary (Algeciras Bay, Cádiz), a eutrophic coastal ecosystem where a green tide episode has been thoroughly studied (Hernández et al. 1997).

Instantaneous effect of a canopy arrangement on photosynthesis. The first laboratory experiment was conducted to study the immediate effect of a change in the light field on the photosynthetic parameters. This change can be followed from variations in the PAR/PUR ratio, which increases through Ulva canopies (Vergara et al. 1997). The PUR, according to Morel $(1978)$, is the product of PAR $(\lambda)$ with a weighting function $[A(\lambda)]$ describing the probability that a photon of a given wavelength will be absorbed by the thallus. The dimensionless variable is derived from the absorption spectrum of Ulva by dividing the spectrum by the maximal absorption $\left(A_{\max }\right)$, which occurs in vivo at $440 \mathrm{~nm}$ (Vergara et al. 1997). Prior to the experiment, $U$. rigida and $U$. rotundata thalli were maintained for $2 \mathrm{~d}$ in filtered natural sea water (Whatman $\mathrm{GF} / \mathrm{C}$ ) in a Koxka EC-540F incubation chamber. Culture conditions were $15^{\circ} \mathrm{C}$, white light of low intensity $(20 \mu \mathrm{mol}$ photons $\mathrm{m}^{-2} \mathrm{~s}^{-1}$, Philips TLD36W/54), and $12 \mathrm{~h}$ light: 12 h dark L/D photoperiod cycle. Photosynthesisphoton fluence rate (P-PFR) curves were calculated using $U$. rigida and $U$. rotundata discs. A variable number of Ulva layers (from 0 to 3 ) were placed between the light source and the oxygen-electrode chamber. These layers were sandwiched between 2 transparent glass plates and wetted with sea water to prevent desiccation (Fig. 1A). This device changed the PAR/PUR ratio of the incident light, as it reduced the amount of photons of blue and red wavelengths (Vergara et al. 1997). Readings of the actual PFR reaching the Ulva discs in the electrode chamber were carried out by placing the detector $(2 \pi$ collector LiCor LI 192 SA connected to a LiCor LI-1000 radiometer) behind the 'Ulva sandwich' Photosynthetic measurements were immediately performed in a Hansatech polarographic $\mathrm{O}_{2}$ electrode at $15^{\circ} \mathrm{C}$, as previously described (Pérez-Lloréns et al. 1996), and P-PFR curves were fitted according to Jassby \& Platt (1976).

Photoacclimation in the laboratory. In this second design, Ulva blades were arranged in canopies either in a permanent position or by random changes of the thalli ( 2 mixings per day), simulating the 2 possible conditions to which the algae can be subjected in the 

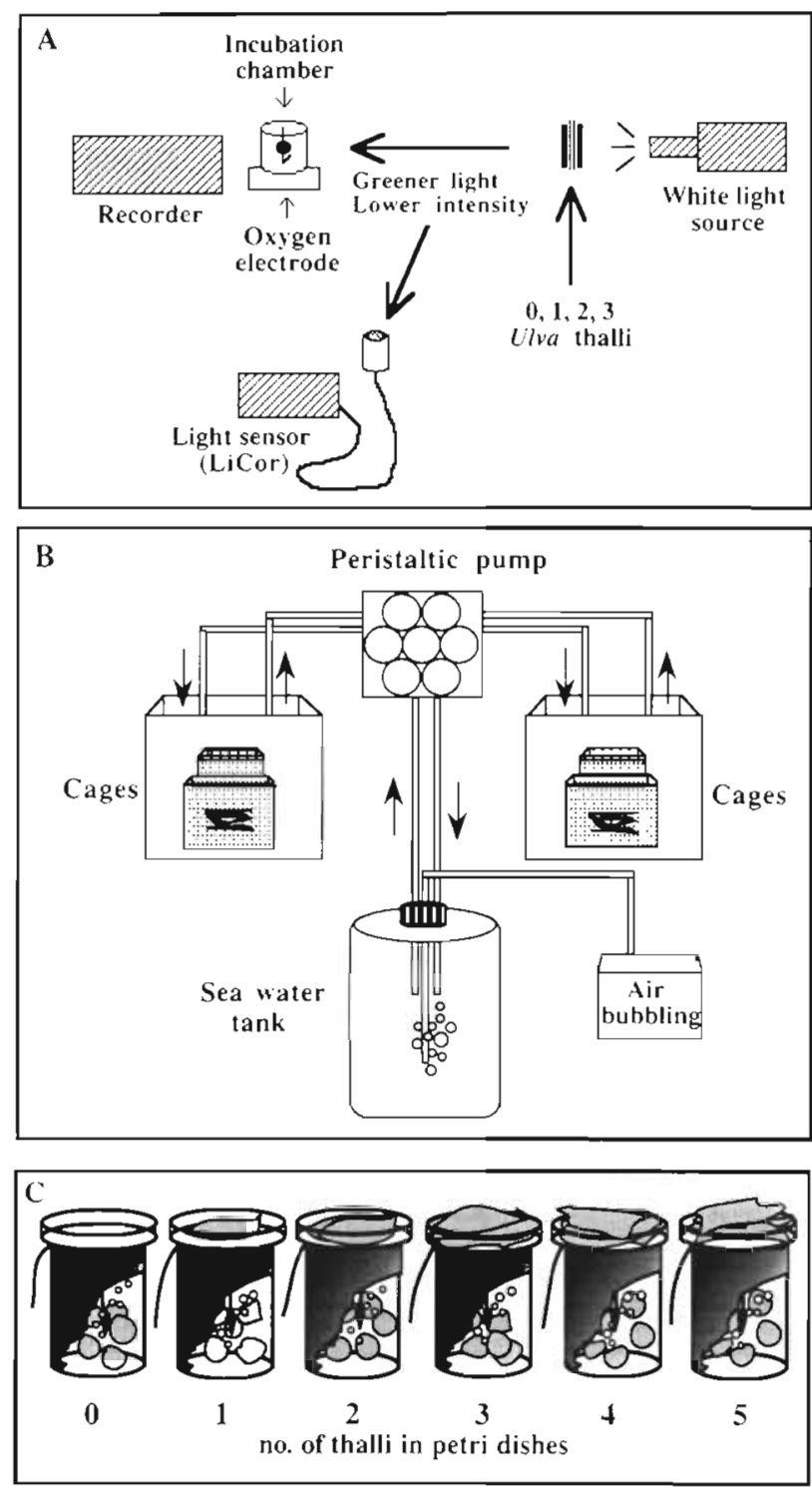

Fig. 1. Experimental designs to study (A) the immediate effect of the change in the light field on the photosynthetic parameters, (B) the photoacclimation in Ulva canopies under laboratory conditions, and $(\mathrm{C})$ the culture of Ulva covered by a variable number of thalli, simulating a dynamic light supply

field (Fig. 1B). Six Ulva thalli of $10 \times 10 \mathrm{~cm}$ area were superimposed within white plastic cages $(16 \times 16 \times$ $5 \mathrm{~cm}$ ) of $1 \mathrm{~cm}$ mesh size. Cages $(n=4)$ were immersed in 2 methacrylate aquaria filled with filtered (Whatman $\mathrm{GF} / \mathrm{C})$ natural air-bubbled sea water. Independent replicates of each treatment were conducted. Each aquarium $(n=2)$ contained 2 cages, one with Ulva thalli in a permanent position and another one with a random arrangement. A continuous closed-flow system was kept by means of a peristaltic pump (WatsonMarlow) at a flow rate of $5 \mathrm{l} \mathrm{d}^{-1}$, with a reservoir of $15 \mathrm{l}$. Incubations were conducted at $15^{\circ} \mathrm{C}$. Incident PFR on the canopies was $160 \mu \mathrm{mol}$ photons $\mathrm{m}^{-2} \mathrm{~s}^{-1}$ (Sylvania GRO-LUX, F-36W/GRO-T8) in a $12 \mathrm{~h}$ light:12 h dark photoperiod. The incubation period was $13 \mathrm{~d}$ for $U$. rigida and $7 \mathrm{~d}$ for $U$. rotundata. This period was shorter in $U$. rotundata, as some signs of sporulation were observed in the margin of some thalli. However, this period of time is sufficient to complete the photoacclimation process in Ulva species (Pérez-Lloréns et al. 1996). After the incubation, growth rate, photosynthetic performance, chlorophyll concentration, wide band absorptance, and C:N atomic ratio were determined as previously described (Pérez-Lloréns et al. 1996), and compared with the initial values. Since the acclimation responses for chlorophyll $a$ and $b$ were similar (data not shown), total chlorophyll data (a plus b) were reported. Because the time to complete P-PFR curves ( 2 replicates $\times 2$ treatments $\times 6$ thalli) was a limiting step, photosynthesis was measured at light saturation ( $715 \mu \mathrm{mol}$ photons $\left.\mathrm{m}^{-2} \mathrm{~s}^{-1}\right)\left(P_{\max }\right)$, at a subsaturating light level ( $48 \mu \mathrm{mol}$ photons $\mathrm{m}^{-2} \mathrm{~s}^{-1}, P_{\text {subsat }}$ ), indicative of photosynthetic efficiency at low light levels (as indicated in previous P-PFR curves) and in darkness $\left(R_{\mathrm{d}}\right)$.

The design shown above did not allow us to record the sequence of changes of the PFR reaching the different Ulva layers in the random arrangement (i.e. the 'light history'; the mean PFR and its variance). Therefore, a further experiment was necessary to follow these PFR changes. The design of this experiment is shown in Fig. 1C. U. rigida discs of $10 \mathrm{~mm}$ diameter $(\mathrm{n}=6)$ were placed in $250 \mathrm{ml}$ aerated beakers $(\mathrm{n}=24)$ with filtered natural sea water, which was replaced every $2 \mathrm{~d}$. The incubations were carried out for $8 \mathrm{~d}$ at $15^{\circ} \mathrm{C}$ with an incident PFR of $160 \mu \mathrm{mol}$ photons $\mathrm{m}^{-2} \mathrm{~s}^{-1}$ in a $12 \mathrm{~h}$ light:12 h dark photoperiod, as described above. Petri dishes were fitted on the top of the beakers. The petri dishes contained a variable number of superimposed Ulva thalli (0 to 5), simulating Ulva canopies of different number of layers (1 to 6). Beakers were wrapped in black plastic bags to prevent light entering other than from the top. Ulva thalli placed in petri dishes were immersed in sea water to prevent desiccation. The position of the petri dishes on the beakers remained fixed in the treatment simulating a stable canopy arrangement, while they were randomly changed (2 times per day in the light period; about 3 and $9 \mathrm{~h}$ after the onset of the light period) in the random treatment. Two replicates per treatment were carried out. After the incubations, growth rate and chlorophyll concentration were measured. The control of the PFR reaching the beakers and the measurement of growth rate and total chlorophyll were performed as described above. The specific attenuation coefficient for PFR was calculated for each petri dish, assuming an exponential model, and was applied to the incident 

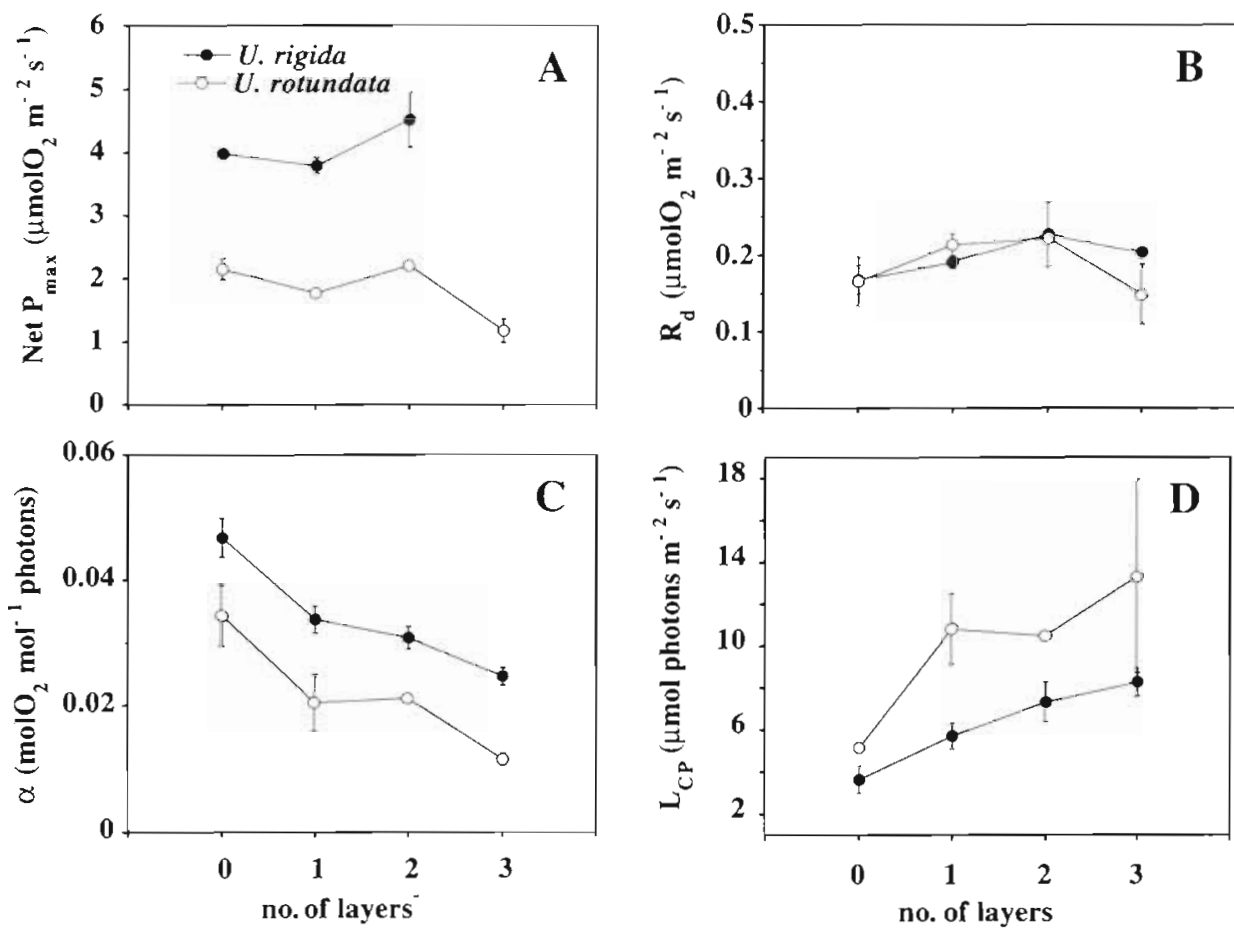

Fig. 2. Ulva rigida and U. rotundata. (A) Light-saturated rate of photosynthesis (net $P_{\max }$ ) (B) dark respiration $\left(R_{\mathrm{d}}\right)_{\mathrm{i}}(\mathrm{C})$ photosynthetic efficiency $(\alpha)_{i}$ and (D) light compensation point $\left(L_{C P}\right)$ as a function of the number of Ulva layers placed between the light source and the incubation chamber. Data are means $\pm \mathrm{SE}(\mathrm{n}=2) . P_{\max }$ under 3 thalli was not computed in $U$. rigida as light was strongly attenuated and no saturating PFRs were obtained
PFR on each treatment in the simulated mixed canopies. This experimental design was also useful for interpreting possible effects of a slow water diffusion within the canopy. This was achieved by comparing the responses of thalli within the canopy (first design) to those of free-floating discs under a simulatedcanopy arrangement (second design).

Photoacclimation in the field. Canopy devices $(n=3)$ for Ulva rigida, like those described in the laboratory experiments (Fig. 1B), were placed at the main flume of a creek in Los Toruños. This location was selected because its proximity to the laboratory allowed daily inspection. To avoid Ulva thalli being lost, cages were covered with a grid of fishing line. The enclosures were attached to plastic rods, which were sunk into the sediment near the low water mark. The incubation period was $12 \mathrm{~d}$. The chlorophyll concentration, absorptance and specific growth rate on an area basis were determined as described above. The field inspection in the Palmones river estuary suggested the stability of canopy arrangements. Thus, 3 random spots of natural canopies of $U$. rotundata were sampled. To analyze the chlorophyll profiles, discs were carefully punched from different layers in the canopies. Immediately after collection, the discs were placed in acetone (24 h, $4^{\circ} \mathrm{C}$ in darkness), and chlorophyll concentration was estimated in the laboratory according to Jeffrey \& Humprey (1975).

Statistical analysis. Significant effects of canopy structure on photoacclimation were assessed by a 1-way analysis of variance (ANOVA). Student's $t$-tests were applied to compare the means of structured versus randomly mixed canopies. The significance of the instantaneous effect of canopy arrangement on photosynthetic parameters was assessed by a simple linear regression test. In all cases the statistical significance was set at $5 \%$ probability (Zar 1984).

\section{RESULTS}

\section{Instantaneous effect of the canopy arrangement on photosynthesis}

The aim of this experiment was to investigate the instantaneous effect of the self-shading on the photosynthetic parameters of Ulva rigida and $U$. rotundata. In both species, the light-saturated rate of photosynthesis $\left(P_{\max }\right)$ and the dark respiration $\left(R_{\mathrm{d}}\right)$ were unaffected by changes in the PAR/PUR ratio (Fig. 2A, B). In contrast, the photosynthetic efficiency $(\alpha)$ and the light compensation point $\left(L_{C P}\right)$ were affected by the spectral change in the light field. In the 2 species, increased self-shading resulted in a decrease of $\alpha$ (Fig. 2C), whereas the $L_{C p}$ increased significantly in $U$. rigida and in $U$. rotundata (Fig. 2D). Interspecific differences were observed for $P_{\max }, \alpha$ and $L_{\mathrm{CP}}$ : U. rigida showed significantly higher values of $P_{\max }$ and $\alpha$ than U. rotundata. 


\section{Photoacclimation of Ulva canopies in the laboratory}

The Ulva thalli acclimated to a canopy arrangement in the laboratory. Total chlorophyll concentration decreased towards the top of the canopies in both species (Fig. 3A, C). As a result, the upper thalli of the mat exhibited lower absorptance values than deeper ones (Fig. 3B, D). In $U$. rigida, total chlorophyll concentration suggested a bell-shaped curve (with a maximum in the fifth layer). This species exhibited higher absorptance values than $U$. rotundata. This resulted in a drastic reduction of the light availability in the bottom layer of the $U$. rigida canopies, which was about $3 \mu \mathrm{mol}$ photons $\mathrm{m}^{-2} \mathrm{~s}^{-1}$, close to the $L_{C P}$ for this species. In $U$. rotundata, the $\mathrm{PFR}$ reaching the bottom layer was much higher (ca $30 \mu \mathrm{mol} \mathrm{m} \mathrm{m}^{-2} \mathrm{~s}^{-1}$ ), as absorptance was lower than in $U$. rigida. Mean chlorophyll concentration and absorptance of thalli from randomly mixed canopies were lower than those in the permanently arranged canopies in $U$. rigida, but not in $U$. rotundata.

The effect of photoacclimation on the photosynthetic characteristics of the canopy arrangement is shown in Fig. 4. $P_{\text {max }}$ and $P_{\text {subsat }}$ (indicative of photosynthetic
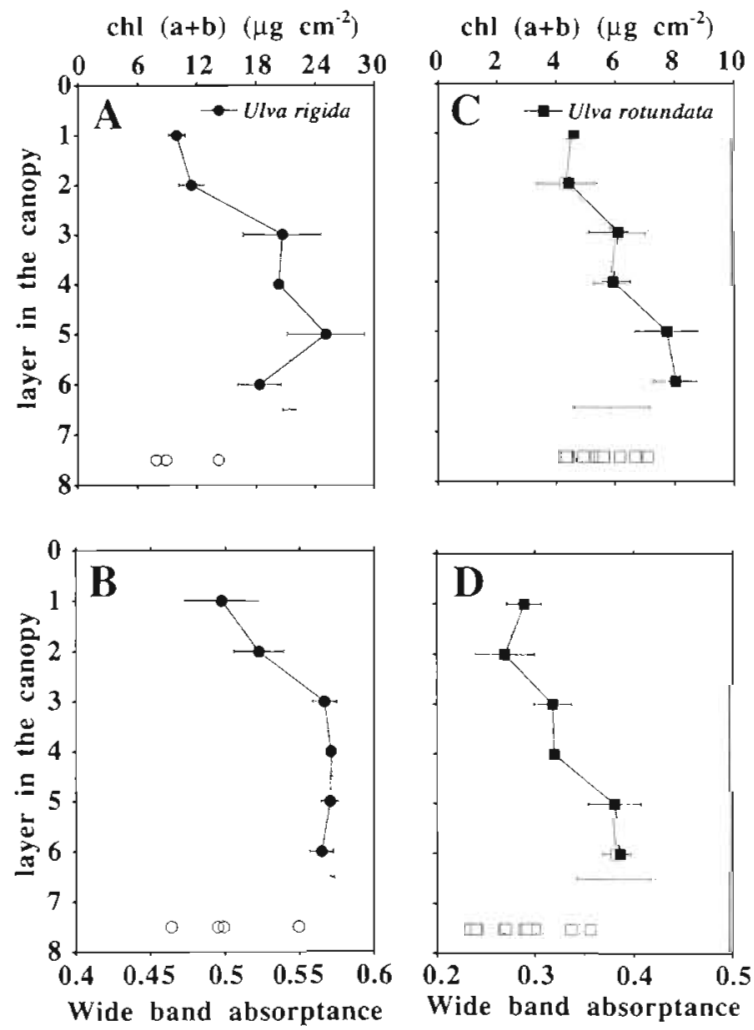

Fig. 3. ( $A, B)$ Ulva rigida and $(C, D)$ U. rotundata. (A, C) Total chlorophyll concentration and $(B, D)$ wide band absorptance as a function of the arrangement within Ulva canopies or as a result of a random disposition (open symbols at the bottom). Vertical dotted lines represent initial values. Data are means $\pm \mathrm{SE}(\mathrm{n}=2)$
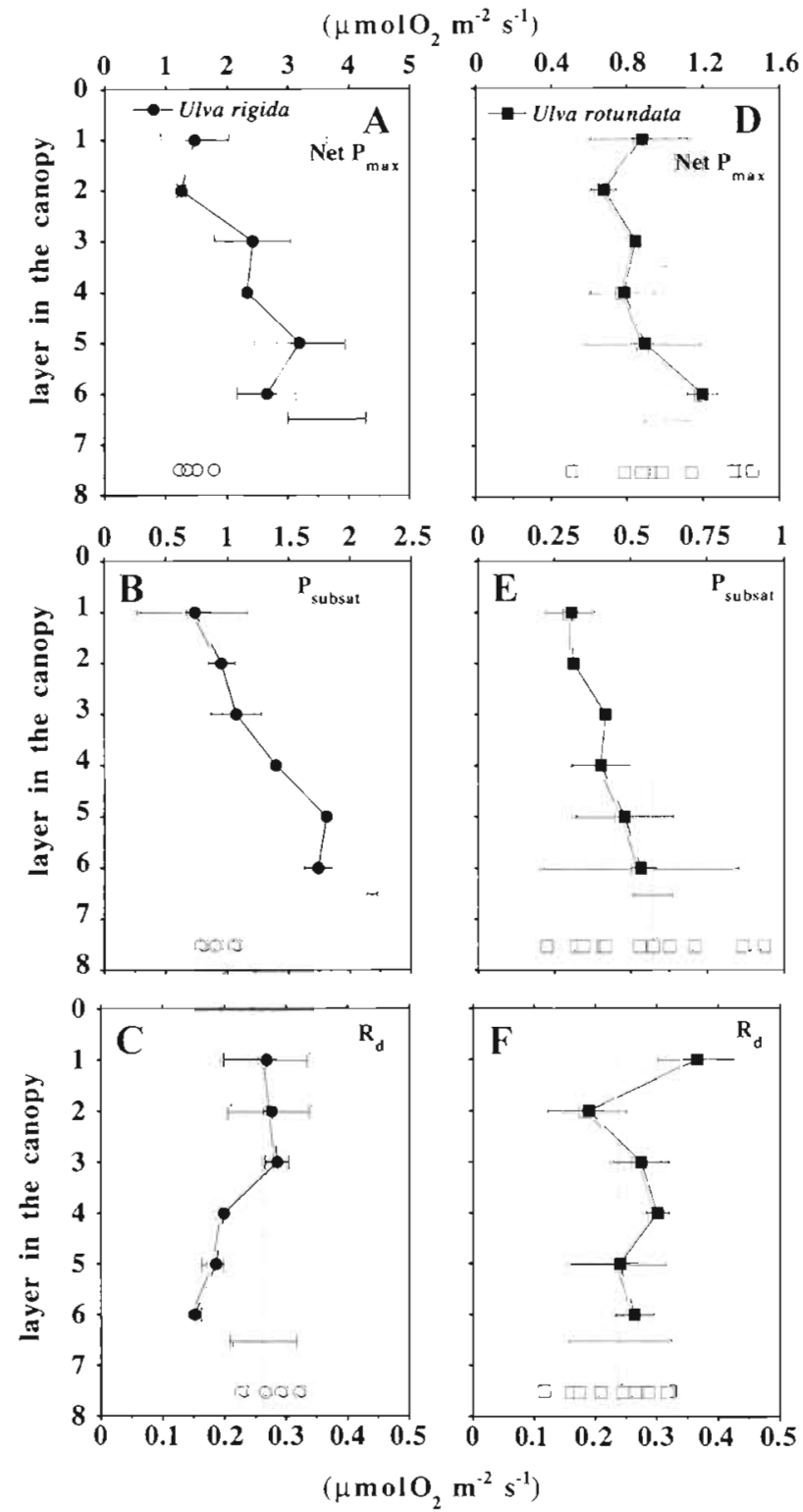

Fig. 4. Effect of canopy disposition on the rate of photosynthesis of $(A-C)$ Ulva rigida and $(D-F)$ U. rotundata at $(A, D)$ light saturation (net $\left.P_{\max }\right),(\mathrm{B}, \mathrm{E})$ subsaturating light level $\left(P_{\text {Subsal }}\right)$, and $(C, F)$ dark respiration $\left(R_{\mathrm{d}}\right)$. Open symbols at the bottom represent values corresponding to randomly mixed canopies. Vertical dotted lines represent initial rates. Data are means \pm $\mathrm{SE}(\mathrm{n}=2)$

efficiency at low light levels) of Ulva rigida decreased towards the top of the canopy. The same trend was observed in $U$. rotundata for $P_{\text {subsal, while } P_{\text {max }} \text { was }}$ not significantly affected. Conversely, $R_{\mathrm{d}}$ in $U$. rigida decreased from the fourth layer to the bottom as compared to the upper layers. In $U$. rotundata mats, $R_{d}$ did not change, except for the higher value in the uppermost layer. $P_{\max }$ and $P_{\text {subsat }}$ were significantly affected by treatment (permanent vs mixed canopies) in $U$. 


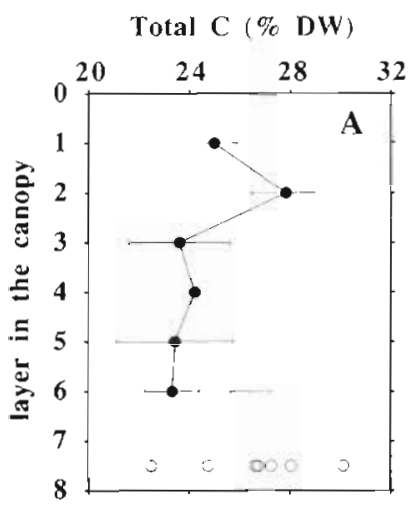

Total N (\% DW $)$
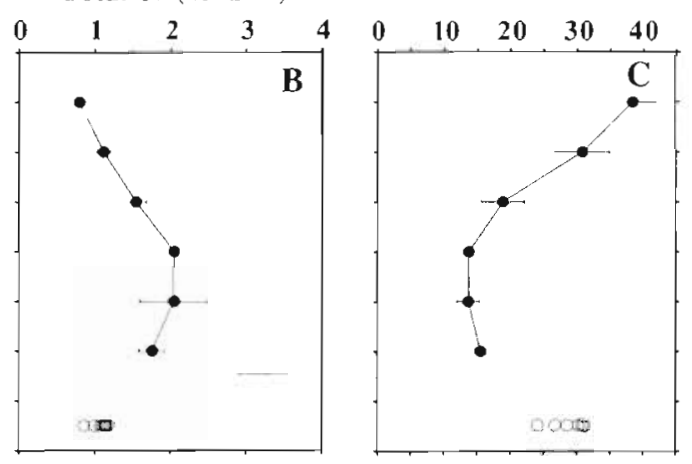

Fig. 5. Ulva rigida. (A) Total internal $C_{\text {, }}$ (B) total internal $N_{1}$ and (C) C:N molar ratio as a function of the arrangement within canopies or as a result of a random disposition (open symbols at the bottom). Vertical dotted lines represent initial values. Data are means \pm SE $(n=2)$. DW: dry weight rigida, but not in $U$. rotundata. In contrast, $R_{\mathrm{d}}$ showed similar values in mixed and permanent canopies in both species.

The C:N atomic ratio exhibited a vertical profile in Ulva rigida that decreased from the top to the fourth layer and from there remained fairly constant down to the bottom layers of the mat (Fig. 5). This pattern was mainly due to the trend of $\mathrm{N}$ content (Fig. 5B). Nitrogen content and the C:N ratio were significantly affected depending on the degree of stability of the canopies. In randomly mixed canopies, values were close to those achieved in the first upper layers of the permanent canopies.

Specific growth rate was a function of the incident PFR within the canopy, decreasing from top to bottom layers. However, growth rates showed a minimum in the middle of the mat in both species (fourth or fifth thallus), increasing again towards the bottom layers (Fig. 6). Randomly mixed thalli displayed higher growth rates than the mean value attained in structured canopies.

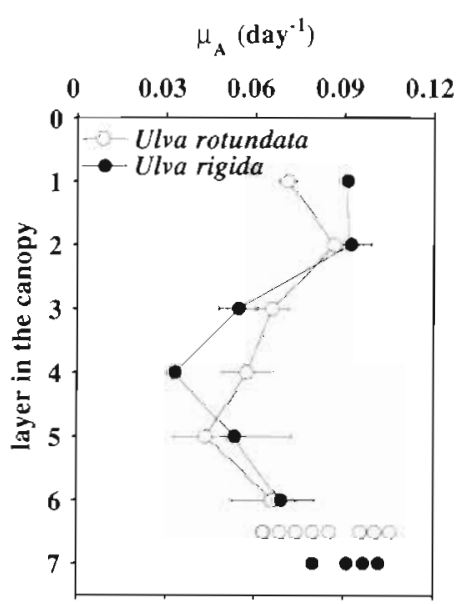

Fig. 6. Ulva rigida and $U$. rotundata. Specific growth rate $\left(\mu_{\mathrm{A}}\right)$ as a function of the position within the canopies or in randomly mixed canopies (symbols at the bottom). Data are means $\pm \mathrm{SE}(\mathrm{n}=2)$
Fig. 7 shows the growth rate and the chlorophyll content of Ulva rigida discs incubated in beakers, simulating a permanent canopy disposition (i.e. petri dishes with 'Ulva screens' always on the top of the same beaker) and a mixed canopy (the position of petri dishes were randomly changed twice per day). As stated in 'Material and methods', this experimental design allowed us to quantify the mean PFR (and its variability) reaching each one of the beakers. Growth rate and the chlorophyll content were affected by PFR under a stable canopy arrangement. Growth rate saturated with increasing PFRs. Chlorophyll concentration peaked at a PFR $=\mathrm{ca} 10 \mu \mathrm{mol}$ photons $\mathrm{m}^{-2} \mathrm{~s}^{-1}$, decayed

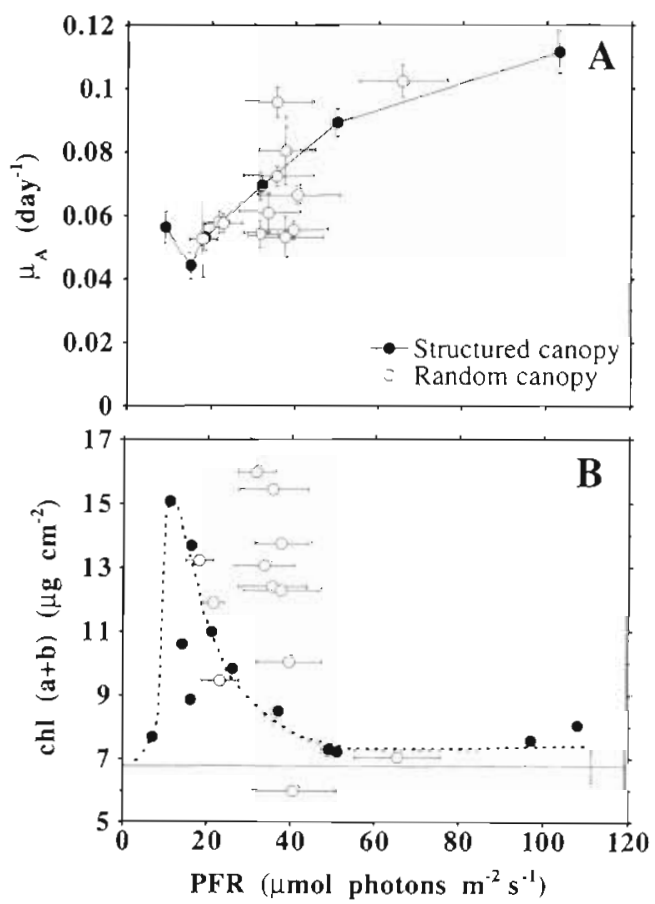

Fig. 7. Ulva rigida. (A) Specific growth rate $\left(\mu_{\mathrm{A}}\right)$ and (B) total chlorophyll as a function of incident (PFR) within structured or randomly mixed canopies. Data for chlorophyll content represent mean values of 5 to $6 U$. rigida discs per treatment. Horizontal line in (B) represents the initial value 
exponentially at higher PFRs, and decreased sharply at very low irradiances.

In those treatments simulating a mixed canopy, the growth rate and the chlorophyll content were highly variable, despite the fact that almost all the beakers received a similar mean PFR (between 30 and $40 \mu \mathrm{mol}$ photons $\mathrm{m}^{-2} \mathrm{~s}^{-1}$ ) and a similar degree of PFR variability (Fig. 7). Growth rates were higher, similar or lower than those attained by thalli receiving a similar but uniform PFR. Chlor ophyll content was also highly variable, generally displaying higher values than those attained by thalli receiving a similar and constant light dose. Besides this variability, growth rate and chlorophyll content were not correlated $(p>0.05)$; that is, the higher chlorophyll contents were not associated with higher or lower growth rates. In addition, chlorophyll content showed no relationship with the last PFR experienced by the thalli. Furthermore, no clear trends were observed in growth rate and chlorophyll content with respect to the order of light fluctuation (data not shown).

\section{Photoacclimation under field conditions}

To evaluate the photoacclimation in response to a canopy arrangement in the field, Ulva rigida canopies were settled in the vicinity of the laboratory (see 'Material and methods'). The vertical profiles of total chlorophyll (Fig. 8), and, similarly, the wide band absorptance (data not shown), indicated that photoacclimation to a stable canopy arrangement was accomplished in the field. The in situ growth rate was a function of incident PFR. These rates were close to those achieved in the laboratory. From the third layer to the bottom, growth was constant at about $0.04 \mathrm{~d}^{-1}$, despite a much lower PFR.

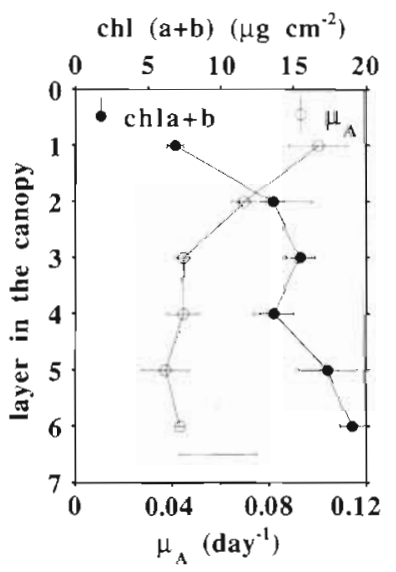

Fig, 8. Ulva rigida. Total chlorophyll and specific growth rate $\left(\mu_{\mathrm{A}}\right)$ of canopies maintained in rectangular cages in the field at Los Toruños creek. Data are means \pm SE $(n=3)$. Vertical dotted line represents the initial total chlorophyll value

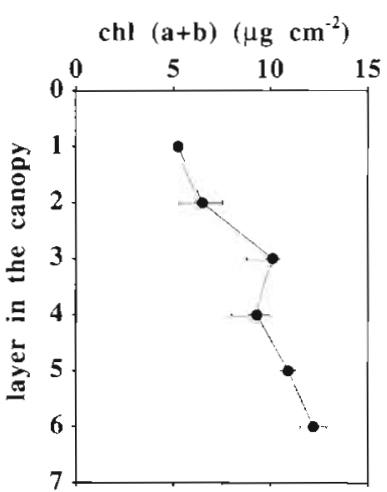

Fig. 9. Ulva rotundata. Vertical profile of total chlorophyll in canopies sampled in Palmones river estuary. Data are means $\pm \mathrm{SE}(\mathrm{n}=3)$

For Ulva rotundata, 3 independent canopy arrangements were randomly sampled in Palmones river estuary. The profile of chlorophyll concentration through the canopy showed evidence of a structured arrangement of the canopies in natural assemblages (Fig. 9), similar to those found in laboratory studies.

\section{DISCUSSION}

The primary production of macroalgal populations depends largely on the photosynthetic performance and on the light availability within macroalgal canopies. Both factors have been assessed in previous studies in Ulva (Vergara et al. 1997) and the rhodophytes Ahnfeltiopsis concinna (J. Ag.) and Laurencia mcdermidiae (J. Ag.) (Beach \& Smith 1996a, b). However, studies of the seasonal variations of light attenuation, pigment content and photosynthesis in Ulva do not consider the photoacclimation to a canopy structure (Vergara et al. 1997). Besides a variable light climate caused by tides in a highly turbid environment, light is further attenuated as a consequence of the canopy arrangement of Ulva thalli (Vergara et al. 1997). In these mats, light is not only attenuated, but also spectrally filtered. If the PAR/PUR ratio increased through the canopy (Vergara et al. 1997), it would be expected that $\alpha$ would decrease and the $L_{C P}$ would show the opposite pattern, while $P_{\max }$ and $R_{\mathrm{d}}$ would be unaffected. The results presented in this study (Fig. 2) corroborate these expectations: there is less photosynthetically usable radiation (PUR; sensu Morel 1978) with depth through the canopies.

The culture of Ulva thalli arranged in permanent canopies showed evidence of photoacclimation. In this study, chlorophyll content of both species acclimated in much the same way as observed in response to irradiance (Pérez-Lloréns et al. 1996). There was an 
inverse relationship between chlorophyll content and incident PFR, as shown by Henley \& Ramus (1989a) and Markager \& Sand-Jensen (1994) in Ulva species, with an eventual minimum at very low light levels, as in Pérez-Lloréns et al. (1996). The profile of the C:N ratio showed a pattern that was similar to that reported in mats of Chaetomorpha linum arranged in the laboratory (Krause-Jensen et al. 1996). Thus, bottom layers will be more light limited, while upper layers will be predominantly $\mathrm{N}$ limited (Lapointe \& Duke 1984, Krause-Jensen et al. 1996). This profile agrees with the chlorophyll data, as chlorophyll concentrations reflect not only the light regime but also the macroalgal $N$ status (Bird et al. 1982, Lapointe \& Duke 1984).

With regard to the photosynthetic parameters, thalli placed deeper in the canopy, and hence submitted to a lower PFR, showed higher photosynthesis rates in comparison to blades located in the upper layers of the mats. This acclimation to low light levels can be considered as adaptive (sensu Givnish 1988, PérezLloréns et al. 1996). Dark respiration, in contrast, was higher at the upper Ulva layers, which is directly related to a higher metabolic requirement for growth (Geider \& Osborne 1992, Pérez-Lloréns et al. 1996). The increase in respiration at the upper layer may be also attributed to the cost of photooxidative damage (Long et al. 1994).

The minimum growth rate was found in the middle of the canopies and may seem, at first, rather unexpected (Fig. 6). To explain this result, the effect of a persistent laminar flow between 2 Ulva layers must be considered (Wheeler 1988). With a mean coefficient of molecular diffusion of $10^{-9} \mathrm{~m}^{2} \mathrm{~s}^{-1}$ for nutrients in sea water (Mann \& Lazier 1996), the time it would take a nutrient to cause an effect over $5 \mathrm{~cm}$ (from the edge to the middle of a thalli of $10 \mathrm{~cm}$ length, in arranged canopies) is about $5000 \mathrm{~s}$ (between 1 and $2 \mathrm{~h}$ ). Thus, this stagnant sea water between the Ulva blades will have a low renewal rate and will become impoverished in inorganic carbon and nutrients, while the $\mathrm{pH}$ will increase and the oxygen will be oversaturated. This explanation has been suggested in Chaetomorpha mats (Krause-Jensen et al. 1996). The relative changes in the proportions of $\mathrm{CO}_{2}$ and $\mathrm{O}_{2}$ may influence the activity of Rubisco (Woodrow \& Berry 1988), negatively affecting photosynthesis and hence growth. In fact, this minimum was not achieved under natural conditions, where the hydrodynamic conditions were stronger than in the laboratory experiments. Thus, besides a light gradient within the mat, the lack of an adequate renewal of sea water may decrease growth in Ulva thalli located inside the mat.

The experiment conducted to assess the effect of a random organization of the thalli within a canopy showed that, in structured canopies, PFR affected growth rate and chlorophyll concentration, whereas the random arrangement displayed high variability despite a similar mean light dose. There is little knowledge of the effect of low frequency (hours) changes in light exposure in marine macroalgae. Henley \& Ramus (1989b) studied the response of light fluctuation on the order of hours on growth and chlorophyll content in Ulva rotundata. They found a relationship between chorophyll content and total daily radiation, while growth rate was dependent on the temporal distribution of light fluctuation. The effects of sunflecks of high frequency (in the time scale of seconds) on photosynthesis have been investigated by Greene \& Gerard (1990) and Kübler \& Raven (1996) in the rhodophytes Chondrus crispus, Palmaria palmata and Lomentaria articulata. However, the mechanisms involved at this time scale will differ from those occurring at longer ones, as physiological responses may depend on the time scale of the fluctuation (Cullen \& Lewis 1988). In microalgae, several studies have been devoted to analyze the primary productivity under a light fluctuation of lower frequency (hours), as vertical mixing may subject phytoplankton populations to a dynamic light supply. These frequencies are usually shorter than the generation time of the cells (Prézelin 1992). Dynamic light with a period of fluctuation of $1 \mathrm{~h}$ has been compared to static light regimes in Chlorella (Kroom et al. $1992 a$ b). In these studies, dynamic light supply caused a lower chlorophyll concentration as well as reduced $P_{\max }$ and $\alpha$. In phytoplankton, the effects of mixing and variable light have been equivocal (Mallin \& Paerl 1992). These authors used a 'light field simulator' to mimic vertical mixing of phytoplankton community. There was a stimulation of growth rate under mixing conditions and a lower chlorophyll concentration in comparison to static light fields. In constant light regimes, at high light intensities, photoinhibition may reduce growth, and, additionally, growth may be restricted under low light (Marra 1978, Gallegos \& Platt 1982). Thus, mixing will alleviate these 2 constraints, stimulating productivity (Harding et al. 1987). In contrast to these arguments, the steep and abrupt changes of PFR applied in our study, simulating a random mix of the thalli, will cause an intermittent and unpredictable stimulation-repression of acclimation processes. Thus, the photosynthetic structures (reaction centres, photosynthetic antenna complexes, electron transport components and enzymatic catalysts) would experience a much higher and variable turnover than under constant light, which may raise the maintenance cost for growth (Raven 1984, PérezLloréns et al. 1996).

The results obtained in the field corroborate those achieved in the laboratory. The chlorophyll profile suggested clear signs of photoacclimation in Ulva rigida 


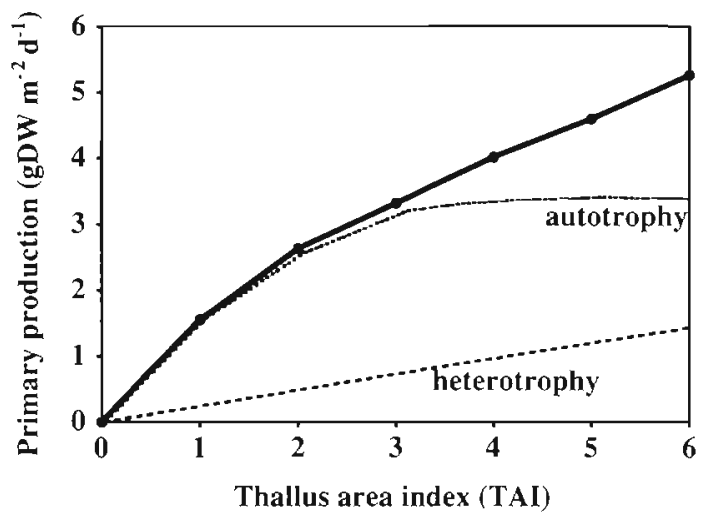

Fig. 10. Ulva rigida. Primary production of canopies settled in the field as a function of the thallus area index (TAI). The experimental data can be interpreted as the sum of a lightsaturated function (autotrophy) plus a light-independent linear one (heterotrophy). DW: dry weight

canopies maintained in cages. With regard to growth, the typical saturation curve of primary production of the population versus TAI was not achieved in $U$. rigida (Fig. 10). Rather, the slope was smoothed as thalli were placed deeper in the canopy, despite a quite low PFR at the bottom layers of the mat, especially at high tide in a highly turbid environment. This could be the result of a double kinetic, a light-dependent saturation curve plus a light-independent linear one, indicative of heterotrophic growth at low light levels (Fig. 10; see also Markager \& Sand-Jensen 1990). This possibility has already been suggested for natural UIva populations (Vergara et al. 1997), as a TAI as high as 17 was occasionally recorded in Palmones river estuary (Hernández et al. 1997). Under such circumstances, light will be completely attenuated through. the mat, and the bottom layers completely darkened. Thus, organic substrates, which are abundant in highly productive environments, such as shallow bays and estuaries (Valiela 1995), may be an additional source for primary production of Ulva species.

Besides field acclimation in Ulva rigida, the vertical chlorophyll gradient found in $U$. rotundata canopies from a natural assemblage is evidence of a stable arrangement of Ulva blades within the stands, although random mixing may occur sporadically in some parts of the Palmones river estuary. Acclimation may have a certain time scale to occur (from hours to days) (Falkowski \& La Roche 1991), and it is clear from the laboratory experiments that chlorophyll concentrations of randomly mixed canopies were not related to the mean light dose received (Fig. 7) nor to the last light regime in the experiments (data not shown).

In conclusion, while the light attenuation caused by Ulva canopies may be included in any model of primary production in these systems (Vergara et al. 1997), the incorporation of the photoacclimation characteristics of Ulva to a canopy arrangement may refine the predictions of the model.

Acknowledgements. This work was supported by the project AMB 96-0782 from the Ministerio Español de Educacion y Cultura. We thank Bill Henley and 3 anonymous reviewers for their comments on the manuscript.

\section{LITERATURE CITED}

Beach KS, Smith CM (1996a) Ecophysiology of tropical rhodophytes. I. Microscale acclimation in photosynthesis. J Phycol 32:701-710

Beach KS, Smith CM (1996b) Ecophysiology of tropical rhodophytes. Il. Microscale acclimation in pigmentation. J Phycol 32:710-718

Bird KT, Habig C, De Busk T (1982) Nitrogen allocation and storage patterns in Gracilaria tikvahiae (Rhodophyta). J Phycol 18:344-348

Cullen JJ, Lewis MR (1988) The kinetics of algal photoadaptation in the context of vertical mixing. J Plankton Res 10: 1039-1063

Falkowski PG, La Roche J (1991) Acclimation to spectral irradiance in algae. J Phycol 27:8-14

Gallegos CL, Platt T (1982) Phytoplankton production and water motion in surface mixed layers. Deep Sea Res 29: $65-76$

Geertz-Hansen O, Enriquez S, Duarte CM, Agustí S, Vaque D, Vidondo B (1994) Functional implications of the form of Codium bursa, a balloon-like Mediterranean macroalga. Mar Ecol Prog Ser 108:153-160

Geider RJ, Osborne BA (1992) Algal photosynthesis. Chapman \& Hall, New York

Givnish TJ (1988) Adaptation to sun and shade: a whole plant perspective. Aust J Plant Physiol 15:63-92

Greene RM, Gerard VJ (1990) Effects of high-frequency light fluctuations on growth and photoacclimation of the red alga Chondrus crispus. Mar Biol 105:337-344

Harding LW, Fisher TR, Tyler MA (1987) Adaptive responses of photosynthesis in phytoplankton: specificity to timescale change in light. Biol Oceanogr 4:403-437

Henley WJ, Ramus J (1989a) Optimization of pigment content and the limits of photoacclimation for Ulva rotundata (Chlorophyta). Mar Biol 103:267-274

Henley WJ, Ramus J (1989b) Photoacclimation and growth rate responses of Ulva rotundata (Chlorophyta) to intraday variations in growth irradiance. J Phycol 25:398-401

Hernández I, Peralta G, Pérez-Lloréns JL, Vergara JJ, Niell FX (1997) Biomass and dynamics of growth of Ulva species in Palmones river estuary. J Phycol 33:764-772

Jassby AD, Platt T (1976) Mathematical formulation of the relationship between photosynthesis and light for phytoplankton. Limnol Oceanogr 21:540-547

Jeffrey SW, Humphrey GF (1975) New spectrophotometric equations for determining chlorophylls $a, b, c_{1}$ and $c_{2}$ in higher plants, algae and natural phytoplankton. Biochem Physiol Pflanz 167:191-194

Kirk JTO (1994) Light and photosynthesis in aquatic ecosystems. Cambridge University Press, Cambridge

Krause-Jensen D, McGlathery K, Rysgaard S, Christensen PB (1996) Production within dense mats of the filamentous macroalga Chaetomorpha linum in relation to light and nutrient availability. Mar Ecol Prog Ser 134:207-21.6 
Kroon BM, Burger-Wiersma T, Visser PM, Mur LR (1992a) The effect of dynamic light regimes in Chlorella: ll. Minimum quantum requirement and photosynthesis-irradiance parameters. Hydrobiologia 238:79-88

Kroon BM, Latasa M, Ibelings BW, Mur LR (1992b) The effect of dynamic light regimes in Chlorella: I. Pigments and cross sections. Hydrobiologra 238:71-78

Kübler JE, Raven JA (1996) Nonequilibrium rates of photosynthesis and respiration under dynamic light supply. J Phycol 32:963-969

Lapointe BE, Duke CS (1984) Biochemical strategies for growth of Gracilaria tikvahiae (Rhodophyta) in relation to light intensity and nitrogen availability. J Phycol 20:488-495

Lassen C, Bebout LE, Paerl HW, Jørgensen BB (1994) Microsensor studies of oxygen and light distribution in the green macroalga Codium fragile. J Phycol 30:381-386

Long SP, Humphries S, Falkowski PG (1994) Photoinhibition of photosynthesis in nature. Annu Rev Plant Physiol Plant Mol Biol 45:655-662

Mallin MA, Paerl HW (1992) Effects of variable irradiance on phytoplankton productivity in shallow estuaries. Limnol Oceanogr 37:54-62

Mann KH. Lazier JRN (1996) Dynamics of marine ecosystems. Biological-physical interactions in the oceans, 2nd edn. Blackwell Science, London

Markager S, Sand-Jensen K (1990) Heterotrophic growth of Ulva lactuca (Chlorophyceae). J Phycol 26:670-673

Markager S, Sand-Jensen K (1994) The physiology and ecology of light-growth relationships in macroalgae. Prog Phycol Res 10:209-298

Marra J (1978) Phytoplankton photosynthetic response to vertical movement in a mixed layer. Mar Biol 46:203-208

Morel A (1978) Available, usable, and stored radiant energy in relation to marine photosynthesis. Deep Sea Res 25: $673-688$

Morel A, Lazzara L, Gostan J (1987) Growth rate and quantum yield time response for a diatom changing irradiances

Editorial responsibility: Otto Kinne (Editor).

Oldendorf/Luhe, Germany (energy and color). Limnol Oceanogr 32:1066-1084

Pérez-Lloréns JL, Vergara JJ, Pino RR, Hernández I, Peralta G. Niell FX (1996) The effect of photoacclimation on the photosynthetic physiology of Ulva curvata and Ulva rotundata (Ulvales, Chlorophyta). Eur J Phycol 31:349-359

Prézelin BB (1992) Diel periodicity of phytoplankton productivity. Hydrobiologia 238:1-35

Raven JA (1984) Energetics and transport in aquatic plants Alan R. Liss, New York

Salles S, Aguilera J, Figueroa FL (1996) Light field in algal canopies: changes in spectral light ratios and growth of Porphyra leucosticta Thur in Le Jol. In: Figueroa FL, Jiménez C, Pérez-Lloréns JL, Niell FX (eds) Underwater light and algal photobiology. Sci Mar 60(Suppl 1):29-38

Schramm W, Nienhuis PH (eds) (1996) Marine benthic vegetation. Recent changes and the effects of eutrophication. Springer-Verlag, Berlin

Terashima I, Hikosaka K (1995) Comparative ecophysiology of leaf and canopy photosynthesis. Plant Cell Environ 18: 1111-1118

Valiela I (1995) Marine ecological processes, 2nd edn. SpringerVerlag, New York

Valiela I, McClelland J, Hauxwell J, Behr PJ, Hersh D, Foreman K (1997) Macroalgal blooms in shallow estuaries: controls and ecophysiological and ecosystem consequences. Limnal Oceanogr 42:1105-1118

Vergara JJ, Pérez-Lloréns JL, Peralta G, Hernández I, Niell FX (1997) Seasonal variation of photosynthetic performance and light attenuation in Ulva canopies from Palmones river estuary. J Phycol 33:773-779

Wheeler WN (1988) Algal productivity and hydrodynamicsa synthesis. Prog Phycol Res 6:23-58

Woodrow BE, Berry JA (1988) Enzymatic regulation of photosynthetic $\mathrm{CO}_{2}$ fixation in $\mathrm{C} 3$ plants. Annu Rev Plant Physiol Plant Mol Biol 39:533-594

Zar JH (1984) Biostatistical analysis, 2nd edn. Prentice Hall, Englewood Cliffs, NJ

Submitted: December 1, 1997; Accepted: February 11, 1998

Proofs received from author(s): March 30, 1998 